\title{
Effect of a Glyphosate-Containing Herbicide on Escherichia coli and Salmonella Ser. Typhimurium in an In Vitro Rumen Simulation System
}

\author{
Katrin Bote $^{1 *}$, Judith Pöppe ${ }^{1}$, Susanne Riede ${ }^{2}$, Gerhard Breves ${ }^{2}$ and Uwe Roesler ${ }^{1}$ \\ ${ }^{1}$ Institute for Animal Hygiene and Environmental Health, Freie Universität Berlin, Berlin, Germany \\ ${ }^{2}$ Institute for Physiology and Cell Biology, University of Veterinary Medicine, Hannover, Germany
}

Received: 13 May 2019; accepted: 28 May 2019

\begin{abstract}
Glyphosate ( $N$-(phosphonomethyl)glycine) is the most-used herbicide worldwide. Many studies in the past have shown that residues of the herbicide can be found in many cultivated plants, including those used as livestock feed. Sensitivity to glyphosate varies with bacteria, particularly those residing in the intestine, where microbiota is exposed to glyphosate residues. Therefore, less susceptible pathogenic isolates could have a distinct advantage compared to more sensitive commensal isolates, probably leading to dysbiosis.

To determine whether the ruminal growth and survival of pathogenic Escherichia coli or Salmonella serovar Typhimurium are higher when glyphosate residues are present in the feed, an in vitro fermentation trial with a "Rumen Simulation System" (RUSITEC) and a glyphosate-containing commercial formulation was performed.

Colony forming units of $E$. coli and Salmonella ser. Typhimurium decreased steadily in all fermenters, regardless of the herbicide application. Minimum inhibitory concentrations of the studied Salmonella and E. coli strains did not change, and antibiotic susceptibility varied only slightly but independent of the glyphosate application.

Overall, application of the glyphosate-containing formulation in a worst-case concentration of $10 \mathrm{mg} / \mathrm{L}$ neither increased the abundance for the tested E. coli and Salmonella strain in the in vitro fermentation system, nor promoted resistance to glyphosate or antibiotics.
\end{abstract}

Keywords: glyphosate, roundup, rumen simulation system, RUSITEC, glyphosate resistance, microbial community, fermentation

\section{Introduction}

The non-selective herbicide glyphosate ( $N$-(phosphonomethyl)glycine) is the active ingredient in the formulation Roundup $^{\circledR}$. Since the introduction of glyphosate-resistant crops in 1996, it became the most-used plant protection product worldwide [1-3]. Glyphosate disrupts the synthesis of aromatic amino acids by inhibiting the enzyme 5-enolpyruvylshikimic acid-3-phosphate synthase (EPSPS) in the shikimate pathway, which is present in plants and microorganisms but not in humans $[4,5]$ and was patented as a broad-spectrum antimicrobial [6]. Various glyphosate-containing products have been approved and are currently available on the market. These formulations usually consist of an active ingredient (glyphosate, often as the isopropylamine salt, IPA), a surfactant to enhance physical and chemical properties (e.g., spreading and absorption), and water [7]. After application, the glyphosate IPA salt dissociates, and the free glyphosate acid is transported into the plant, where it becomes active [8].

Intensive use of glyphosate has been associated with increased resistance in plants, while glyphosate residues are routinely detected along the food production chain and in the environment. The herbicide has been detected in soybeans [9-14], maize [15, 16], canola [17], and poultry and cattle feed [18], as well as in urine samples of humans and cows [19-21]. Data regarding the amount of residues vary depend-

\footnotetext{
*Author for correspondence: Institute for Animal Hygiene and Environmental Health, Robert-von-Ostertag-St. 7-13, 14163, Berlin, Germany; E-mail: Katrin. Bote@fu-berlin.de and E-mail: tierhygiene@vetmed.fu-berlin.de; Phone: +49 30838 51845; Fax: +4930838451863.
}

ing on the time of harvest, particular pesticide regulations in different countries, and the applied formulation. In soybeans, the detected amount of glyphosate ranges from $100 \mathrm{ng} / \mathrm{g}$ in seeds or $780 \mathrm{ng} / \mathrm{g}$ in leaves up to $450 \mathrm{ng} / \mathrm{g}$ or $7790 \mathrm{ng} / \mathrm{g}$, respectively [14]. For maize, a maximum of $40 \mathrm{ng} / \mathrm{g}$ in seeds and about $420 \mathrm{ng} / \mathrm{g}$ in leaves has been detected, whereby residues on fields with a history of previous glyphosate treatment had higher levels compared to first-treatment fields [16]. In barley and oats, $5.85 \mathrm{mg} / \mathrm{kg}$ glyphosate has been measured [13]. Overall, Reuter et al. saw the possibility of crops to accumulate up to $252 \mathrm{mg}$ glyphosate per $\mathrm{kg}$ [17], but data about the level of glyphosate residues in prepared livestock feed are sparse. Shehata et al. estimated $0.4-0.9 \mathrm{mg} / \mathrm{kg}$ in poultry and cattle feed in Germany [22]. In order to identify how much glyphosate remains in cattle feed after the harvest, Schnabel et al. treated wheat and peas with the formulation Roundup $^{\circledR}$ Record according to the legal European Union (EU) regulations and determined an intake of 73.8 or $84.5 \mathrm{mg}$ glyphosate per cow per day, depending on the proportion of concentrate in the total mixed ration [23]. A small amount of glyphosate is potentially degraded to aminomethylphosphonic acid (AMPA) in the rumen [24].

Considering the shared metabolic pathway in plants and bacteria, which is targeted by glyphosate, it is conceivable that glyphosate may further influence bacterial communities that come in contact with it. Indeed, it has been demonstrated that pathogenic bacteria are likely to be more resistant to glyphosate than commensals [22, 25]. E. coli and Salmonella enterica are two zoonotic bacterial species commonly found in livestock animals, as well as in meat samples after slaughtering [26]. Transmission of multidrug-resistant bacteria such as

This is an open-access article distributed under the terms of the Creative Commons Attribution-NonCommercial 4.0 International License (https://creativecommons.org/licenses/by-nc/4.0/), which permits unrestricted use, distribution, and reproduction in any medium for non-commercial purposes, provided the original author and source are credited, a link to the CC License is provided, and changes - if any - are indicated. 
Table 1. Overview of the strains used to infect the RUSITEC fermentation vessels with the inoculum quantity and the used resistances to detect the isolates on our agar plates. Minimum inhibitory concentration (MIC) was determined for isopropylamine glyphosate in the formulation Roundup LB Plus (RU, registration number 024142-00) with and without $\mathrm{pH}$ adjustment with $\mathrm{NaOH}$

\begin{tabular}{lcccc}
\hline Species & MIC RU & MIC RU pH7 & Original host & Selectivity resistances \\
Salmonella ser. Typhimurium & $80 \mathrm{mg} / \mathrm{mL}$ & $80 \mathrm{mg} / \mathrm{mL}$ & Pig & Inoculum \\
E. coli & $40 \mathrm{mg} / \mathrm{mL}$ & $80 \mathrm{mg} / \mathrm{mL}$ & Cow & Nalidixic acid \\
\hline
\end{tabular}

extended-spectrum-beta-lactamase (ESBL) producers along the food production chain has attracted a lot of attention in recent years [27]. However, little is known about the effects of glyphosate residues on colonization and/or infection of farm animals with E. coli or Salmonella spp.

Varying sensitivities to glyphosate are likely to result in bacterial composition shifts in favor of more resistant pathogenic isolates, leading to dysbiosis and a possible loss of protecting opportunistic bacteria [17, 25, 28, 29], along with a potential risk of increased shedding and zoonotic transmission. It has been shown in bees that glyphosate can interfere with gut colonization as well [30].

Sub-lethal glyphosate concentrations could further induce resistances and lead to changing antibiotic susceptibility profiles [31-33], with the possibility of transferring antibiotic resistances between isolates from livestock and humans as another major concern [34]. Our own recent studies showed small but significant increases in minimum inhibitory concentrations (MICs) of glyphosate and a commercial glyphosate-containing formulation in Salmonella enterica isolated in recent years in Germany, when compared to historic isolates [35]. Similarly, this was indicative for glyphosate and E. coli [36].

Therefore, in the present study, we sought to understand whether the presence of glyphosate residues in feed may give an advantage to pathogenic enteric bacteria in colonization and infection of livestock, particularly cattle. For this, the in vitro effects of a glyphosate-containing formulation on growth, survival, and resistance of E. coli and Salmonella ser. Typhimurium at a worst-case glyphosate concentration [23] were investigated using the "Rumen Simulation Technique" (RUSITEC) [37].

\section{Materials and Methods}

The used in vitro fermentation system (RUSITEC) was run as described by Riede et al. [37].

RUSITEC Set-up. For inoculation of the RUSITEC fermenter, ruminal content from 3 ruminally fistulated, nonlactating Holstein-friesian cows, fed with $25 \%$ grass silage, $25 \%$ maize silage, and $50 \%$ concentrate, was obtained. The liquid and solid contents were separated by gauze filtration. Six fermentation vessels $(V=700 \mathrm{~mL})$ were filled with the rumen liquid. Seventy grams of solid digesta were inserted into a nylon bag $(11.5 \mathrm{~m} \times 6.5 \mathrm{~cm}$, pore size $150 \mu \mathrm{m})$. A second nylon bag was filled with $15 \mathrm{~g}$ of fresh substrate (49.5\% grass silage, $39.7 \%$ maize silage, $5 \%$ wheat meal, $5 \%$ soy cake, and $0.8 \%$ mineral feed). Both nylon bags were introduced into each fermentation vessel. On the next day, the bag with the original rumen solid content was replaced with another substrate bag, and the day after that, the former feeding bag was exchanged, leading to a retention time of $48 \mathrm{~h}$ for each bag.

The $\mathrm{pH}$ and redox potential $(\mathrm{mV})$ were measured daily prior to feeding, as well as the effluent volume. Concentrations of $\mathrm{NH}_{3}$ and short chain fatty acids (SCFA) were determined at the end of the equilibration period on day 6 .

Infection of the Fermenters. After 7 days of equilibration, each fermentation vessel was inoculated with $1 \mathrm{~mL}$ of an E. coli and a Salmonella ser. Typhimurium strain, respectively. Therefore, overnight cultures of the isolates were subcultured in Mueller Hinton I (CM0405 Oxoid Ltd., Hampshire) and grown to a concentration of $10^{9}$ colony forming units (cfu) $/ \mathrm{mL}$ each to obtain $10^{6} \mathrm{cfu} / \mathrm{mL}$ in the fermenter (Table 1).

The E. coli strain was initially isolated from a lactating cow with acute mastitis and provided by the German Federal Office of Consumer Protection and Food Safety. It is classified as an ESBL-E. coli and, among others, resistant to enrofloxacin and cefotaxime. To recover this isolate from the rumen fluid, CHROMagar ${ }^{\mathrm{TM}}$ Orientation (Merck KgaA, Darmstadt) supplemented with $4 \mu \mathrm{g} / \mathrm{mL}$ enrofloxacin and $2 \mu \mathrm{g} / \mathrm{mL}$ cefotaxime was thus used. The MIC for Roundup ${ }^{\circledR}$ LB Plus (RU, registration number $024142-00$ ) was $40 \mathrm{mg} / \mathrm{mL}$ isopropylamine glyphosate (IPA).

The Salmonella Typhimurium DT104 strain used in this study was initially isolated from a pig and was provided by the German Federal Institute for Risk Assessment. Selective XLD media (Oxoid GmbH, Wesel, Germany) was used to reisolate the strain from the fermenter. The initial MIC for RU was $80 \mathrm{mg} / \mathrm{mL}$ IPA.

After inoculation of the strains, 3 out of 6 fermenters (fermenter numbers 2, 4, and 6) were challenged with the common glyphosate-based herbicide RU containing $360 \mathrm{~g} / \mathrm{L}$ glyphosate (RU), whereas the other fermenters (fermenter numbers 1, 3, and 5) served as controls (CTRL).

Schnabel et al. determined a daily glyphosate intake of up to $84.5 \mathrm{mg}$ per day for lactating dairy cows [23]. Rounding this value to $100 \mathrm{mg}$ per day and taking the rumen content volume (about $100 \mathrm{~L}$ ) into account, we established a daily glyphosate exposure level of $1 \mathrm{mg} / \mathrm{L}$ rumen content. To create a worst-case scenario, RU was added to obtain 10 times of this concentration $(10 \mathrm{mg} / \mathrm{L})$ daily.

Strains were enumerated from the rumen fluid by standard dilution plating on respective selective agar plates at different time points after inoculation $(0,0.5,2,4,8,12,24,48,72$, $96,120,144$, and $168 \mathrm{~h}$ ). If the strains were no longer quantitatively detectable, rumen samples were enriched overnight in buffered peptone water (DM494D Mast Group Ltd., Merseyside) and streaked out for qualitative analysis on the respective selective agar, as described above.

Susceptibility Testing. Three isolates of each strain from each fermenter and the last sampling time point from which bacteria could be recovered were further assessed for changes in antimicrobial susceptibility relative to the original parent strains. Prior to the fermenter experiments, the initial MICs of RU and RU supplemented with $\mathrm{NaOH}$ (to achieve $\mathrm{pH} 7$ ) for these isolates were determined as described previously $[35,36]$. In short, serial twofold dilutions of RU in Mueller Hinton broth ranging from $160 \mathrm{mg} / \mathrm{mL}$ to $2.5 \mathrm{mg} / \mathrm{mL}$ IPA were prepared in conical 96 -well plates and stored at $-80{ }^{\circ} \mathrm{C}$ until use.

For one of the isolates each, antibiotic susceptibility testing via VITEK ${ }^{\circledR}$ system (bioMérieux Deutschland GmbH, Nürtingen, Germany) with the test card VITEK $^{\circledR} 2$ AST N-248 with common relevant antibiotics (piperacillin, piperacillintazobactam, cefotaxime, ceftazidime, cefepime, aztreonam, imipenem, meropenem, amikacin, gentamicin, tobramycin, ciprofloxacin, moxifloxacin, tigecycline, fosfomycin, and trimethoprim/sulfomethoxazole) was further performed.

$E$. coli isolates were further tested for the presence of betalactamase genes $b l a_{\mathrm{CTX}-\mathrm{M}}, b l a_{\mathrm{SHV}}, b l a_{\mathrm{TEM}}$ and the CIT-type 


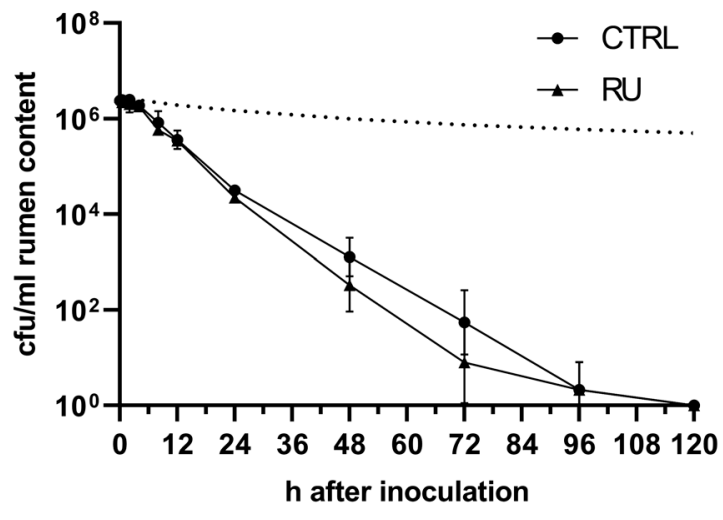

Figure 1. E. coli in the fermentation vessels measured by standard dilution plating on CHROMagar supplemented with $4 \mu \mathrm{g} / \mathrm{mL}$ enrofloxacin and $2 \mu \mathrm{g} / \mathrm{mL}$ cefotaxime. Control group (CTRL) without any glyphosate compared to the group treated with a worst-case amount of glyphosate in the formulation Roundup LB Plus $(10 \mathrm{mg} / \mathrm{L}$, $\mathrm{RU})$. The dotted line represents the theoretical loss of the E. coli due to the wash-out effect of the buffer if bacteria would be in a steady state.

pAmpC genes (blaCMY), following the protocol described by Roschanski et al. [38].

Statistical Analysis. All statistical analyses were performed using IBM ${ }^{\circledR}$ SPSS $^{\circledR}$ Statistics Version 24. All fermenters were compared at each time point individually with a $t$-test. To compare vessels with and without Roundup ${ }^{\circledR}$, the median of the bacterial counts in each fermenter group was calculated and compared with either a non-parametric Wilcoxon test or a t-test. Further, to determine potential statistical differences in qualitative analysis, a chi-squared test was performed when possible (i.e., where not all results were the same).

Ethics. With the study being in vitro, working with an artificial fermentation system in the lab, no ethical approval needed to be obtained. Rumen fluid extraction was executed in accordance with the German Animal Welfare Act approved by the Lower Saxony State Office for Consumer Protection and Food Safety (LAVES, Oldenburg, Germany).

\section{Results}

To determine the effects of the glyphosate-containing formulation Roundup ${ }^{\circledR}$ LB Plus on growth and survival of $E$. coli and Salmonella ser. Typhimurium, we enumerated bacterial counts of the isolates after inoculation in vitro by means of the "Rumen Simulation Technique" (RUSITEC) and standard dilution plating.

E. coli in the Fermenters. After inoculation of $1.27 \mathrm{E}$ +09 cfu E. coli, the median starting concentrations in the fermenters were $2.73 \mathrm{E}+06 \mathrm{cfu} / \mathrm{mL}$ in the CTRL group and $3.12 \mathrm{E}+06 \mathrm{cfu} / \mathrm{mL}$ in the vessels, where RU equivalent to $10 \mathrm{mg} / \mathrm{L}$ glyphosate was added.

In both groups, the concentration of $E$. coli did not vary significantly within the first $2 \mathrm{~h}$. After $12 \mathrm{~h}$, one logarithm step less was detectable, followed by a steady decline of about one to one and a half logarithm steps each day. At day 4 no more $E$. coli were quantitatively detectable in two out of three fermenters of each group (CTRL and RU). Qualitatively E. coli was still present in 5 out of 6 fermenter vessels on day 4 but not anymore on day 5 . An overview of the $\mathrm{cfu} / \mathrm{ml}$ rumen content can be found in Figure 1.

Salmonella Ser. Typhimurium in the Fermenters. In addition to $E$. coli, vessels were simultaneously co-inoculated with $1.02 \mathrm{E}+09$ cfu of the Salmonella ser. Typhimurium strain. Initial median starting concentrations were $1.50 \mathrm{E}+06 \mathrm{cfu} / \mathrm{mL}$ in the CTRL and $1.43 \mathrm{E}+06 \mathrm{cfu} / \mathrm{mL}$ in the RU group. After
$30 \mathrm{~min}$ in both groups, the bacterial counts declined slightly followed by an increase after 2 and $4 \mathrm{~h}$, where approximately the double amount of Salmonella compared to the starting concentrations could be detected $(3.24 \mathrm{E}+06 \mathrm{cfu} / \mathrm{mL}$ after $2 \mathrm{~h}$ in the RU treated group and $3.22 \mathrm{E}+06 \mathrm{cfu} / \mathrm{mL}$ after $4 \mathrm{~h}$ in the CTRL group). This was followed by a steady decline in both groups (Figure 2). At the end of the experiment after 7 days, only $10 \mathrm{cfu} / \mathrm{mL}$ in the CTRL and $90 \mathrm{cfu} / \mathrm{mL}$ in the RU group were still present.

Comparison of the Treated and Non-treated Fermenters. Comparing the median from the control and the worst-case group, no statistically significant differences could be found in Salmonella ser. Typhimurium $(P=0.753)$ and $E$. coli $(P=0.678)$ using Wilcoxon-test analysis or $P=0.967$ and $P=0.825$ using a $t$-test, respectively. More detailed statistical comparisons of all vessels at each sampling point are presented in Table 2.

Ruminal metabolism in the system was checked via $\mathrm{pH}$ and redox potential measurement (Table 3). Values were constant during the experiment in all fermentation vessels. SCFA and $\mathrm{NH}_{3}$ have been checked after adaptation of the ruminal system and before the start of the experiment to ensure proper ruminal settings (data not shown).

Susceptibility Testing. MIC measurements were carried out for 3 isolates of each strain and fermenter from the last sampling point, which displayed bacterial growth. For E. coli, isolates recovered at day 2 from fermenters 2,4 , and 5 and at day 3 from the fermenters 1, 3, and 6 were investigated. Salmonella Typhimurium isolates were examined after 5 days for all fermenters. The MIC values for RU did not change compared to the ancestor (Table 4).

Further, for one isolate of each strain and fermenter, antibiotic susceptibility testing by VITEK ${ }^{\circledR}$ was performed. Individual strains differed in MIC for single antibiotics compared to the ancestor (Table 5). Differences were, in general, in the dimension of 1 or 2 dilution steps except for $E$. coli in cefepime, where ancestor showed a MIC of $\geq 64 \mu \mathrm{g} / \mathrm{mL}$, and the isolates from Fermenter 1, 4, and 5, a MIC of $4 \mu \mathrm{g} / \mathrm{mL}$.

In addition, the $E$. coli isolates were tested for ESBL genes using multiplex real-time polymerase chain reaction (PCR). Isolates from all fermenters as well as the ancestor were positive for CTX and negative for SHV, TEM, and AmpC (data not shown).

\section{Discussion}

In recent years, glyphosate residues have been detected in plants that are commonly used as animal feed, especially in soy [9-13], in farm animal feed [18], and in animals themselves $[20,39]$. Therefore, intestinal bacteria of livestock are exposed to these residues, whereby in general, pathogenic bacteria seem to be more resistant to glyphosate than commensals [22], leading to dysbiosis with corresponding effects on health $[25,28,40]$.

This study thus aimed to determine possible effects or advantages of glyphosate residues on growth and survival for E. coli and Salmonella ser. Typhimurium isolates in vitro by means of the Rumen Simulation System (RUSITEC).

The Number of inoculated E. coli decreased steadily in all fermenters until after $120 \mathrm{~h}$, where no quantitative or qualitative detection was anymore possible on the selective agar plates. No difference has been detected between the CTRL and the RU group, neither quantitatively nor qualitatively.

In an artificial rumen experiment inoculated with sheep content by Bach et al., the amount of E. coli O157:H7 similarly decreased over time [41]. After 120 h, no quantitative detection was possible. Qualitative analyses were negative, 


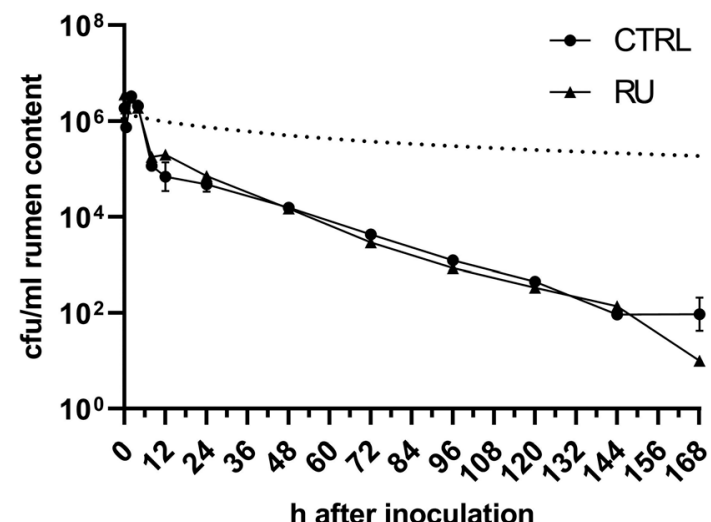

Figure 2. Salmonella ser. Typhimurium in the fermentation vessels measured by standard dilution plating XLD agar. Control group (CTRL) without any glyphosate compared to the group treated with a worst-case amount of glyphosate in the formulation Roundup LB Plus $(10 \mathrm{mg} / \mathrm{L}, \mathrm{RU})$. The dotted line represents the theoretical loss of the Salmonella due to the wash-out effect of the buffer if bacteria would be in a steady state.

$168 \mathrm{~h}$ after inoculation, respectively. The decline in the amount of $E$. coli is slightly slower but comparable to the results in this study, indicating a normal process for an in vitro ruminal setting.

With a first small initial drop and a following short peak, the amount of Salmonella ser. Typhimurium in the fermenters declined as well. In contrast to E. coli, Salmonella was quantitatively detectable until the end of the experiment on day 7 . However, only a few bacteria survived regardless of the RU treatment.

As seen in an in vivo study by Brownlie and Grau, elimination of different Salmonella spp. in the rumen is common [42]. Twenty-four hours after inoculation, the bacteria were no more detectable, when cows were fed normally. The numbers of Salmonella spp. remained the same or increased only when the daily feed intake was reduced. The following starvation was accompanied by a decreased amount of volatile fatty acids and an increased pH. Although the amount of Salmonella in the in vivo study from Brownlie and Grau decreased faster compared to our in vitro results, the trend is comparable.

The addition of RU did not cause changes in basic rumen fermentation parameters $(\mathrm{pH}$ and redox potential), in agreement with other studies [37, 43].

Bacterial exposure to glyphosate or similar biocides is known to facilitate emergence of resistance against the agents

Table 2. Statistical analysis of the differences between the control vessels and the vessels with $10 \mathrm{mg} / \mathrm{L}$ Roundup as a worst-case scenario for each sampling point quantitatively with the $t$-test. Further, a qualitative analysis with a chi-squared test for $E$. coli was performed (x: incalculable, because all fermenters are equal). No significant difference between the groups at any sampling point

\begin{tabular}{|c|c|c|c|c|}
\hline \multicolumn{2}{|c|}{ Time point } & \multicolumn{2}{|r|}{$t$-test } & \multirow{2}{*}{$\frac{\text { Chi-squared test }}{E \text {. coli }}$} \\
\hline & & E. coli & Salmonella ser. Typhimurium & \\
\hline$\overline{\mathrm{P} 0}$ & Inoculation & $P=0.244$ & $P=0.855$ & $\mathrm{x}$ \\
\hline $\mathrm{P} 1$ & $0,5 \mathrm{~h}$ & $P=0.558$ & $P=0.503$ & $\mathrm{x}$ \\
\hline $\mathrm{P} 2$ & $2 \mathrm{~h}$ & $P=0.456$ & $P=0.309$ & $\mathrm{x}$ \\
\hline P3 & $4 \mathrm{~h}$ & $P=0.706$ & $P=0.970$ & $\mathrm{x}$ \\
\hline P4 & $8 \mathrm{~h}$ & $P=0.275$ & $P=0.540$ & $\mathrm{x}$ \\
\hline P5 & $12 \mathrm{~h}$ & $P=0.687$ & $P=0.539$ & $\mathrm{x}$ \\
\hline P6 & $24 \mathrm{~h}$ & $P=0.151$ & $P=0.792$ & $\mathrm{x}$ \\
\hline P7 & $48 \mathrm{~h}$ & $P=0.178$ & $P=0.339$ & $\mathrm{x}$ \\
\hline P8 & $72 \mathrm{~h}$ & $P=0.257$ & $P=0.355$ & $P=0.273$ \\
\hline P9 & $96 \mathrm{~h}$ & $P=1.000$ & $P=0.534$ & $P=0.273$ \\
\hline $\mathrm{P} 10$ & $120 \mathrm{~h}$ & - & $P=1.000$ & $\mathrm{x}$ \\
\hline P11 & $144 \mathrm{~h}$ & - & $P=0.729$ & $P=0.273$ \\
\hline P12 & $168 \mathrm{~h}$ & - & $P=0.163$ & $\mathrm{x}$ \\
\hline
\end{tabular}

Table 3. Control of ruminal metabolism. Means of the treated (RU) and non-treated (CTRL) vessels on each day of the experiment

\begin{tabular}{lcccc}
\hline $\begin{array}{l}\text { Days after } \\
\text { inoculation }\end{array}$ & \multicolumn{2}{c}{ CTRL } & \multicolumn{2}{c}{ RU } \\
\cline { 2 - 5 } & $\mathrm{pH}$ & $\begin{array}{c}\text { Redox potential } \\
(\mathrm{mV})\end{array}$ & $\mathrm{pH}$ & $\begin{array}{c}\text { Redox potential } \\
(\mathrm{mV})\end{array}$ \\
\hline 0 & 6.66 & -273 & 6.65 & -274 \\
1 & 6.70 & -281 & 6.64 & -279 \\
2 & 6.66 & -261 & 6.68 & -278 \\
3 & 6.67 & -277 & 6.69 & -282 \\
4 & 6.69 & -279 & 6.74 & -281 \\
5 & 6.71 & -281 & 6.70 & -272 \\
6 & 6.66 & -264 & 6.67 & -282 \\
7 & 6.67 & -265 & 6.63 & -264 \\
Mean & 6.68 & -273 & 6.68 & -276 \\
& $6.69 \pm$ & $271 \pm 10$ & $6.68 \pm$ & $273 \pm 9$ \\
\hline
\end{tabular}

themselves [33, 44-48]. Furthermore, a shift in antibiotic susceptibility can be associated with sub-inhibitory concentrations of glyphosate [31, 32] or biocides [33, 46, 49, 50]. Most adaptions are based on non-specific mechanisms, such as an increase in efflux pump activity [32, 44, 49, 50]. To test the possibility of increased resistance following the exposure to RU, strains from the last time point with detectable bacterial growth in each fermenter have been tested for changes in their MIC for RU using broth microdilution and a panel of antibiotics using VITEK ${ }^{\circledR}$.

Even though some authors suggest that exposure to glyphosate can lead to increased expression of efflux pumps [32, 44], all tested strains did not vary in MIC for RU compared to their ancestral strain. This corroborates the results of an evolutionary mutagenesis study of Tincher et al., in which an $E$. coli $\mathrm{K}-12$ wild-type and mutant strain had been exposed to the formulation Roundup ${ }^{\circledR}$ concentrate Plus for longer terms without detecting any mutagenesis [51]. Considering the MIC of $40 \mathrm{mg}$ IPA per $\mathrm{mL}$ for $E$. coli or $80 \mathrm{mg}$ IPA per $\mathrm{mL}$ for Salmonella ser. Typhimurium, respectively, the used strains require a large amount of active ingredient to be overcome until a change in MIC via broth microdilution is visibly detectable. Additionally, the worst-case glyphosate dosage of $10 \mathrm{mg} / \mathrm{L}$ is substantially lower than the MIC of the inoculated strains. It is therefore possible that isolates were not challenged enough to adapt.

However, regarding antibiotic susceptibility, few changes could be found by VITEK $^{\circledR}$ analysis. Most of the changes seemed negligible, having been only within the range of 1 dilution step for Salmonella ser. Typhimurium or 2 dilution steps for $E$. coli, respectively. The sole exception was the susceptibility against the fourth-generation cephalosporin cefepime in E. coli, where in the tested isolates of fermenter 1 (CTRL), 4 (RU), and 5 (CTRL), the MIC decreased within 4 dilution steps.

The influence of glyphosate-based herbicides on antibiotic susceptibility is supported by Kurenbach et al. [31], who

Table 4. Minimum inhibitory concentrations (MIC) of isolated bacteria at the time point of the experiment with still solid growth on agar plates in comparison to the ancestral strain. MIC for IPA was tested in Roundup (RU) and RU adjusted to $\mathrm{pH} 7$ (RU pH 7) (F: fermentation vessel)

\begin{tabular}{|c|c|c|c|c|c|c|c|c|c|}
\hline \multirow[t]{2}{*}{$\overline{\mathrm{F}}$} & \multirow[t]{2}{*}{$\mathrm{RU}$} & \multicolumn{4}{|c|}{ E. coli } & \multicolumn{4}{|c|}{ Salmonella ser. Typhimurium } \\
\hline & & \multicolumn{4}{|c|}{$\begin{array}{l}\text { Sample DayMIC RUMIC RU pH } \\
\text { number } \quad(\mathrm{mg} / \mathrm{mL}) \quad(\mathrm{mg} / \mathrm{mL})\end{array}$} & \multicolumn{4}{|c|}{$\begin{array}{c}\text { T Sample DayMIC RUMIC RU } \\
\text { number } \quad(\mathrm{mg} / \mathrm{mL}) \quad \mathrm{pH} 7 \\
(\mathrm{mg} / \mathrm{mL})\end{array}$} \\
\hline 1 & - & P8 & 3 & 40 & 80 & $\mathrm{P} 10$ & 5 & 80 & 80 \\
\hline 2 & + & P7 & 2 & 40 & 80 & $\mathrm{P} 10$ & 5 & 80 & 80 \\
\hline 3 & - & P8 & 3 & 40 & 80 & $\mathrm{P} 10$ & 5 & 80 & 80 \\
\hline 4 & + & P7 & 2 & 40 & 80 & $\mathrm{P} 10$ & 5 & 80 & 80 \\
\hline 5 & - & P7 & 2 & 40 & 80 & $\mathrm{P} 10$ & 5 & 80 & 80 \\
\hline 6 & + & P8 & 3 & 40 & 80 & $\mathrm{P} 10$ & 5 & 80 & 80 \\
\hline \multicolumn{2}{|c|}{ Ancestor } & & & 40 & 80 & & & 80 & 80 \\
\hline
\end{tabular}


Table 5. Minimum inhibitory concentrations in $\mu \mathrm{g} / \mathrm{mL}$ tested with the VITEK ${ }^{\circledR}$ system and the test card AST N-248 with common relevant antibiotics. Shown in bold are the differences compared to the ancestor strain (R: resistant; $\mathrm{S}=$ susceptible)

\begin{tabular}{|c|c|c|c|}
\hline & Ceftazidime & Cefepime & $\overline{\text { Aztreonam }}$ \\
\hline E. coli Ancestor & $16 \mathrm{R}$ & $\geq 64$ & $16 \mathrm{R}$ \\
\hline E. coli Fermenter 1 & $16 \mathrm{R}$ & $\overline{4}$ & $\geq 64 \mathrm{R}$ \\
\hline E. coli Fermenter $4^{a}$ & $4 \mathrm{~S}$ & 4 & $\geq 64 \mathrm{R}$ \\
\hline E. coli Fermenter 5 & Piperacillin/Tazobactam & Moxifloxacin & \\
\hline Salmonella ser. Typhimurium Ancestor & $8 \mathrm{~S}$ & $0.5 \mathrm{~S}$ & \\
\hline Salmonella ser. Typhimurium Fermenter 1 & $\leq 4 \mathrm{~S}$ & $1 \mathrm{R}$ & \\
\hline Salmonella ser. Typhimurium Fermenter 3 & $\leq 4 \mathrm{~S}$ & $0.5 \mathrm{~S}$ & \\
\hline${ }^{a}$ Fermenter belonging to the RU treated & & & \\
\hline
\end{tabular}

measured enhanced and decreased tolerances for different antibiotics after exposure to Roundup ${ }^{\circledR}$ weed killer in an in vitro experiment with single cultures. In their study, however, the Salmonella strain used was less susceptible to ampicillin, ciprofloxacin, and kanamycin and more susceptible to chloramphenicol and tetracycline. Similarly, changes in antibiotic susceptibility in bacteria have been found after biocide exposure. Molina-González et al. identified differences in susceptibility testing for antibiotics, depending on the Salmonella strain and the substance [49]. Likewise, an adaptation to biocides can be accompanied by a resistance to some antibiotics in E. coli [33]. An increase in resistance is detected in most cases. In contrast to these findings, there are also reports showing no change in antibiotic susceptibility after biocide exposure [47, 48, 50]. With conditions similar to our study, Karatzas et al. exposed Salmonella ser. Typhimurium as well to steady sub-inhibitory biocide concentrations for a week with no effect on antibiotic susceptibility. Only when the biocide concentration was increased gradually, a change in susceptibility for some antibiotics could be observed [50]. Condell et al. examined 189 Salmonella enterica strains with 7 commercially available biocides, observing an impact on the tolerance against the active compounds of the biocides but not against complex formulations or different antibiotics [47]. Likewise, this has been shown for other enteric bacteria such as E. coli [48].

Considering the accumulated evidence in the literature, resistances against a biocide or a herbicide such as glyphosate are often but not always accompanied by a change in antimicrobial susceptibility. As indicated by Wales and Davies, controlled laboratory studies may not be the most suitable way to draw conclusions for biocides and microorganism interactions [52]. Nonetheless, using the RUSITEC fermentation system provided more realistic conditions than sole laboratory in vitro studies. No adaptive resistance mechanisms leading to increased MIC for RU, and only slight changes in antibiotic susceptibility have been observed. Notably, the tolerance variations in the latter were equally measured in control and RU fermenters, regardless of the added herbicide.

Overall, no benefits for growth and survival of the tested pathogenic E. coli and Salmonella ser. Typhimurium strains with a worst-case glyphosate concentration of $10 \mathrm{mg} / \mathrm{L}$ present in the formulation Roundup ${ }^{\circledR}$ LB Plus could be detected in the in vitro rumen simulation system. Bacterial counts decreased equally in all fermenters. The MIC against RU did not change and antibiotic susceptibility only changed slightly for some antibiotics and strains regardless of glyphosate exposure.

Considering that there are various glyphosate-containing formulations on the market available worldwide, our findings are restricted to our experimental setup, where complete formulation Roundup ${ }^{\circledR}$ LB Plus and specific E. coli and Salmonella ser. Typhimurium isolates were used. We demonstrated that the worst-case concentration of Roundup has no effect on the pathogenic Enterobacteriaceae under our experimental conditions within a RUSITEC system. It therefore remains to be shown whether other formulations or pure glyphosate would influence the bacterial community in a fermenter model or in monogastric animals in vivo.

\section{Funding Sources}

The project was supported by funds of the Federal Ministry of Food and Agriculture (BMEL) based on a decision of the Parliament of the Federal Republic of Germany via the Federal Office for Agriculture and Food (BLE) (Grant number: 314-06.01-2815HS015).

We acknowledge support by the German Research Foundation and the Open Access Publication Fund of the Freie Universität Berlin.

\section{Authors' Contributions}

K.B. performed the experiments, collected, analyzed and interpreted the data, and drafted the manuscript and figures, with critical evaluation and support of all other authors. J.P. performed the experiments and collected the data. S.R. helped in designing the experiment and gave advice during the whole execution. U.R. and G.B. conceived and designed the study and critically revised the manuscript. All authors approved the final version to be published.

\section{Conflicts of Interest}

The authors declare that they have no conflict of interest.

Acknowledgments. We gratefully acknowledge Dr. Olga Makarova of Freie Universitaet Berlin for her valuable comments on experimental design and the manuscript. We would like to further thank the colleagues at the Institute for Animal Hygiene, Animal Welfare and Farm Animal Behaviour, the University of Veterinary Medicine Hannover for excellent technical support, and the Institute of Animal Nutrition at the Federal Research Institute for Animal Health as well as Dr. Dirk von Soosten for providing ruminal content and support. We acknowledge the Federal Office of Consumer Protection and Food Safety for providing the E. coli isolate and the Federal Institute for Risk Assessment for providing the Salmonella ser. Typhimurium isolate for the study.

\section{References}

1. Duke SO. The history and current status of glyphosate. Pest Manag Sci. 2018;74(5):1027-34.

2. Benbrook CM. Trends in glyphosate herbicide use in the United States and globally. Environmental sciences Europe. 2016;28(1):3 .

3. Green JM. The rise and future of glyphosate and glyphosate-resistant crops. Pest Manag Sci. 2018;74(5):1035-9.

4. Alibhai MF, Stallings WC. Closing down on glyphosate inhibition-with a new structure for drug discovery. Proc Natl Acad Sci U S A. 2001;98(6):2944-6. 
5. Herrmann KM, Weaver LM. The Shikimate Pathway. Annu Rev Plant Physiol Plant Mol Biol. 1999;50:473-503.

6. William A, inventor Glyphosate Formulations And Their Use For The Inhibition Of 5-enolpyruvylshikimate-3-phosphate Synthase. 2002

7. Giesy JP, Dobson S, Solomon KR. Ecotoxicological Risk Assessmen for Roundup ${ }^{\circledR}$ Herbicide. In: Ware GW, editor. Reviews of Environmental Contamination and Toxicology: Continuation of Residue Reviews. New York, NY: Springer New York; 2000. p. 35-120.

8. Williams GM, Kroes R, Munro IC. Safety evaluation and risk assessment of the herbicide Roundup and its active ingredient, glyphosate, for humans. Regul Toxicol Pharmacol. 2000;31(2 Pt 1):117-65.

9. Lorenzatti E, Maitre MI, Argelia L, Lajmanovich R, Peltzer P, Anglada M. Pesticide residues in immature soybean in Argentina croplands. Fresenius Environ Bull. 2004;13(7):675-8.

10. Arregui MC, Lenardon A, Sanchez D, Maitre MI, Scotta R, Enrique S. Monitoring glyphosate residues in transgenic glyphosate-resistant soybean. Pest Manage Sci. 2004;60(2):163-6. [Research Support, Non-U.S. Gov't].

11. Bøhn T, Cuhra M, Traavik T, Sanden M, Fagan J, Primicerio R. Compositional differences in soybeans on the market: glyphosate accumulates in Roundup Ready GM soybeans. Food Chem. 2014;153:207-15. [Comparative Study Research Support, Non-U.S. Gov't].

12. Mesnage R, Defarge N, Spiroux de Vendomois J, Seralini GE. Potential toxic effects of glyphosate and its commercial formulations below regulatory limits. Food Chem Toxicol. 2015;84:133-53. [Research Support, Non-U.S. Gov't Review].

13. Stephenson CL, Harris CA. An assessment of dietary exposure to glyphosate using refined deterministic and probabilistic methods. Food Chem Toxicol. 2016;95:28-41.

14. Duke SO, Rimando AM, Reddy KN, Cizdziel JV, Bellaloui N, Shaw $\mathrm{DR}$, et al. Lack of transgene and glyphosate effects on yield, and mineral and amino acid content of glyphosate-resistant soybean. Pest Manag Sci. 2018;74(5):1166-73

15. Costa FR, Rech R, Duke SO, Carvalho LB. Lack of effects of glyphosate and glufosinate on growth, mineral content, and yield of glyphosate- and glufosinate-resistant maize. GM Crops Food. 2018:1-10.

16. Reddy KN, Cizdziel JV, , Williams MM2nd, Maul JE, Rimando AM, Duke SO. Glyphosate Resistance Technology Has Minimal or No Effect on Maize Mineral Content and Yield. J Agric Food Chem 2018;66(39):10139-46.

17. Reuter T, Alexander TW, Martínez TF, McAllister TA. The effect of glyphosate on digestion and horizontal gene transfer duringin vitro ruminal fermentation of genetically modified canola. J Sci Food Agric. 2007;87(15):2837-43.

18. Shehata AA, Kühnert M, Haufe S, Krüger M. Neutralization of the antimicrobial effect of glyphosate by humic acid in vitro. Chemosphere. 2014;104:258-61.

19. Krüger M, Schledorn P, Schrödl W, Hoppe H-W, Lutz W, Shehata AA. Detection of Glyphosate Residues in Animals and Humans. Journal of Environmental \& Analytical Toxicology 2014;04(02):210

20. Krüger M, Schrödl W, Neuhaus J, Shehata AA. Field Investigations of Glyphosate in Urine of Danish Dairy Cows. Journal of Environmental \& Analytical Toxicology. 2013;03(05):186

21. Conrad A, Schroter-Kermani C, Hoppe HW, Ruther M, Pieper S, Kolossa-Gehring M. Glyphosate in German adults - Time trend (2001 to 2015) of human exposure to a widely used herbicide. Int J Hyg Environ Health. 2017;220(1):8-16.

22. Shehata AA, Schrodl W, Aldin AA, Hafez HM, Kruger M. The effect of glyphosate on potential pathogens and beneficial members of poultry microbiota in vitro. Curr Microbiol. 2013;66(4):350-8.

23. Schnabel K, Schmitz R, Soosten Dvon, Frahm J, Kersten S, Meyer U, et al. Effects of glyphosate residues and different concentrate feed proportions on performance, energy metabolism and health characteristics in lactating dairy cows. Arch Anim Nutr. 2017;71(6):413-27.

24. Soosten Dvon, Meyer U, Huther L, Danicke S, Lahrssen-Wiederholt $\mathrm{M}$, Schafft $\mathrm{H}$, et al. Excretion pathways and ruminal disappearance of glyphosate and its degradation product aminomethylphosphonic acid in dairy cows. J Dairy Sci. 2016;99(7):5318-24.

25. Krüger M, Shehata AA, Schrodl W, Rodloff A. Glyphosate suppresses the antagonistic effect of Enterococcus spp. on Clostridium botulinum Anaerobe. 2013;20:74-8.

26. Safety FOoCPaF. BVL-Report 12.2 - Berichte zur Lebensmittelsicherheit - Zoonosen-Monitoring 2016. Federal Office of Consumer Protection and Food Safety; 2017

27. German Federal Institute for Risk Assessment. ESBL-bildende Bakterien in Lebensmitteln und deren Übertragbarkeit auf den Menschen. Stellungnahme Nr. 002/2012 2011; Available from: https://www.bfr.bund.de/ $\mathrm{cm} / 343 /$ esbl-bildende-bakterien-in-lebensmitteln-und-deren-uebertragbarkeitauf-den-menschen.pdf.

28. Ackermann W, Coenen M, Schrodl W, Shehata AA, Krüger M. The influence of glyphosate on the microbiota and production of botulinum neurotoxin during ruminal fermentation. Curr Microbiol. 2015;70(3):374-82.

29. Aitbali Y, Ba-M'hamed S, Elhidar N, Nafis A, Soraa N, Bennis M. Glyphosate based- herbicide exposure affects gut microbiota, anxiety and depression-like behaviors in mice. Neurotoxicol Teratol. 2018;67:44-9.
30. Motta EVS, Raymann K, Moran NA. Glyphosate perturbs the gut microbiota of honey bees. Proc Natl Acad Sci U S A. 2018;115(41):10305-10.

31. Kurenbach B, Marjoshi D, Amabile-Cuevas CF, Ferguson GC, Godsoe W, Gibson P, et al. Sublethal exposure to commercial formulations of the herbicides dicamba, 2,4-dichlorophenoxyacetic acid, and glyphosate cause changes in antibiotic susceptibility in Escherichia coli and Salmonella enterica serovar Typhimurium. mBio. 2015;6(2). [Research Support, Non-U. S. Gov't].

32. Kurenbach B, Gibson PS, Hill AM, Bitzer AS, Silby MW, Godsoe W, et al. Herbicide ingredients change Salmonella enterica sv. Typhimurium and Escherichia coli antibiotic responses. Microbiology. 2017;163(12):1791-801.

33. Capita R, Riesco-Pelaez F, Alonso-Hernando A, Alonso-Calleja C. Exposure of Escherichia coli ATCC 12806 to sublethal concentrations of foodgrade biocides influences its ability to form biofilm, resistance to antimicrobials, and ultrastructure. Appl Environ Microbiol. 2014;80(4):1268-80.

34. Aarestrup FM, Wegener HC, Collignon P. Resistance in bacteria of the food chain: epidemiology and control strategies. Expert Rev Anti Infect Ther. 2008;6(5):733-50

35. Pöppe J, Bote K, Merle R, Makarova O, Roesler U. Minimum Inhibitory Concentration of Glyphosate and a Glyphosate-Containing Herbicide in Salmonella enterica Isolates Originating from Different Time Periods, Hosts, and Serovars. European Journal of Microbiology and Immunology. 2019.

36. Bote K, Pöppe J, Merle R, Makarova O, Roesler U. Minimum Inhibitory Concentration of Glyphosate and of a Glyphosate-Containing Herbicide Formulation for Escherichia coli Isolates - Differences Between Pathogenicand Non-pathogenic Isolates and Between Host Species. Frontiers in Microbiology. 2019;10:932.

37. Riede S, Toboldt A, Breves G, Metzner M, Kohler B, Braunig J, et al. Investigations on the possible impact of a glyphosate-containing herbicide on ruminal metabolism and bacteria in vitro by means of the 'Rumen Simulation Technique'. J Appl Microbiol. 2016;121(3):644-56.

38. Roschanski N, Fischer J, Guerra B, Roesler U. Development of a multiplex real-time PCR for the rapid detection of the predominant betalactamase genes CTX-M, SHV, TEM and CIT-type AmpCs in Enterobacteriaceae. PLoS ONE. 2014;9(7):e100956.

39. Krüger M, Schrödl W, Pedersen I, Schledorn P, Shehata AA. Detection of Glyphosate in Malformed Piglets. Journal of Environmental \& Analytical Toxicology. 2014;04:230.

40. Lozano VL, Defarge N, Rocque LM, Mesnage R, Hennequin D, Cassier R, et al. Sex-dependent impact of Roundup on the rat gut microbiome. Toxicol Rep. 2018;5:96-107.

41. Bach SJ, McAllister TA, Veira DM, Gannon VPJ, Holley RA. Effect of bacteriophage DC22 on Escherichia coli $\mathrm{O} 157: \mathrm{H} 7$ in an artificial rumen system (Rusitec) and inoculated sheep. Anim Res. 2003;52(2):89-101.

42. Brownlie LE, Grau FH. Effect of Food Intake on Growth and Survival of Salmonellas and Escherichia coli in the Bovine Rumen. J Gen Microbiol. 1967(46):125-34.

43. Huther L, Drebes S, Lebzien P. Effect of glyphosate contaminated feed on rumen fermentation parameters and in sacco degradation of grass hay and corn grain. Arch Anim Nutr. 2005;59(1):73-9.

44. Staub JM, Brand L, Tran M, Kong Y, Rogers SG. Bacterial glyphosate resistance conferred by overexpression of an E. coli membrane efflux transporter. J Ind Microbiol Biotechnol. 2012;39(4):641-7.

45. Fei YY, Gai JY, Zhao TJ. Identification of regulated genes conferring resistance to high concentrations of glyphosate in a new strain of Enterobacter. FEMS Microbiol Lett. 2013;349(2):135-43.

46. Meyer B, Cookson B. Does microbial resistance or adaptation to biocides create a hazard in infection prevention and control? J Hosp Infect. 2010;76(3):200-5.

47. Condell O, Iversen C, Cooney S, Power KA, Walsh C, Burgess C, et al. Efficacy of biocides used in the modern food industry to control salmonella enterica, and links between biocide tolerance and resistance to clinically relevant antimicrobial compounds. Appl Environ Microbiol. 2012;78(9):3087-97.

48. Ledder RG, Gilbert P, Willis C, McBain AJ. Effects of chronic triclosan exposure upon the antimicrobial susceptibility of 40 ex-situ environmental and human isolates. J Appl Microbiol. 2006;100(5):1132-40.

49. Molina-González D, Alonso-Calleja C, Alonso-Hernando A, Capita R Effect of sub-lethal concentrations of biocides on the susceptibility to antibiotics of multi-drug resistant Salmonella enterica strains. Food Control. 2014;40:329-34

50. Karatzas KA, Webber MA, Jorgensen F, Woodward MJ, Piddock LJ, Humphrey TJ. Prolonged treatment of Salmonella enterica serovar Typhimurium with commercial disinfectants selects for multiple antibiotic resistance, increased efflux and reduced invasiveness. J Antimicrob Chemother. 2007;60(5):947-55

51. Tincher $\mathrm{C}$, Long $\mathrm{H}$, Behringer $\mathrm{M}$, Walker $\mathrm{N}$, Lynch $\mathrm{M}$. The Glyphosate-Based Herbicide Roundup Does not Elevate Genome-Wide Mutagenesis of Escherichia coli. G3 (Bethesda). 2017;7(10):3331-5.

52. Wales AD, Davies RH. Co-Selection of Resistance to Antibiotics, Biocides and Heavy Metals, and Its Relevance to Foodborne Pathogens. Antibiotics (Basel). 2015;4(4):567-604. 